\title{
ON PERSPECTIVING \\ IN COGNITIVE GRAMMAR AND COMMUNICATIVE DYNAMISM
}

\author{
Emanuel Sunarto \\ Sanata Dharma University
}

\begin{abstract}
The article is concerned with the concept of 'perspective' in Cognitive Grammar and Communicative Dynamism. To the former, 'perspective' is understood in the realm of cognitive concepts such as space, motion, locationality, directionality, importance, and focus ascribable to a particular sentence segment. To the latter, 'perspectiving' is a matter of valuating, viz. assigning informational value to a sentence segment as a part of a distributional field of communicative dynamism. The two streams of thought evidently hold different constructs per-taining to the term 'perspective': conceptual-categorial on the one hand, and functional-informational on the other. However, the two seem to agree when 'perspectiving' is concerned with the notion of importance and focus or rhematization.
\end{abstract}

Keywords: perspective, importance, focus, informative value, rhematization

\section{A. INTRODUCTION}

By definition, perspective is "a specific point of view in understanding or judging things or events, esp. one that shows them in their true relations to one another", or, "the way in which a matter is judged so that (proper) consideration and importance is given to each part" (WNWCD, LDOCE). In the commonest sense, perspective is "analogous with looking at an everyday object from in front, from the sides, from behind, from on top etc." Viewing, perspectiving, or seeing something for understanding relations and judgmental purposes can be in any of the following four ways: (a) as a whole consisting of parts; (b) as a kind, in contrast with other kinds; (c) as having a certain function; and (d) from the point of view of its origins (Cruse, 2000: 117-119). In linguistics, this very word 'perspective' has also become a key concept in notably two schools of thought, namely Cognitive Grammar (CG) and Communicative Dynamism (CD). How does each conceptualize the very same term? Do they have things in common, and/or in what way does each show its peculiarity? This article is essentially a comparative review and account of the term perspective in the two schools of thought of linguistics.

\section{B. COGNITIVE GRAMMAR}

\section{Cognitive Grammar in a Nutshell}

Cognitive Grammar (CG) was initiated and developed by Langacker (1981, 1991). It is the school of linguistics that understanding language creation, learning, and usage and human cognition is to be made coreferential and complementary. In other words, language is inseparable from cognition and cognition is an indispensable, determinative factor in understanding language. As the name suggests, language is essentially 
cognitively-driven, and, being so, any description of it is to be made with reference to cognitive processing. In other words, language manifests and represents cognitive enterprise. To the cognitive grammarians, grammatical structures are matters of symbols and concepts. Since language and cognition intermingle, there is no need to distinguish nor separate grammar from semantics. What is commonly called 'parts of speech' or linguistic categories such as noun and verb are conceived by advocates of CG as conceptual models of partitioning of reality (Saeed, 2003: 375).

\section{Perspective in Cognitive Grammar}

Perspective in CG is concerned with the notion of viewpoint and focus. It reflects the observer/speaker's cognitive process and decision pertaining to scenes; in particular, the selective viewpoint and the choice of elements to focus on (Langaker 1987, in Saeed, 2003: 377). CG reserves the dictionary definition of 'viewpoint' and is understood in the context of how relations and interactions among the categorial elements in a scene are perceived and conceived (recall Cruse's point (b) and (c) mentioned previously). Sentence constructions are therefore understood as reflections of the observer/speaker's cognitive process of perspectiving or viewpointing. Quoting Saeed's example (2003: 377), if the speaker's perspective is concerned with the house, as in

The children ran around the house.

the phrase can be viewed either externally or internally. Being viewed externally as a container, such a phrase describes a scene where the children's motion circles the outside of the house. Meanwhile, when it is internally viewed, the children are moving around within the house internal space. The phrase the house, along with the preposition around, triggers and activates the cognitive concepts of space and motion (locational-directional-positional).

The spatial concept is therefore inherent to the house being conceived as a selectively focused entity.

CG-perspectiving is not confined to spacial and motional matters. Reserving the observer/speaker's autonomy to decide which element or sentence segment is rendered important and focused, perspectiving can in fact be directed to any of the three segments, the children (agent-perspective), ran (event/activity-perspective), or around the house (settingperspective).

CG-perspectiving may be more easily observed in the process called construal, namely, the speaker's active characterization of scene employing conventional concept-ualization of language and a range of cognitive processes (Langacker, 1987: 101-105; Saeed, 2003: 376). A scene can be viewed either as a sequence or a summary. The sentence

\section{Ruud kicked the ball}

demonstrates the speaker's active characterization of scene as a sequence of activity, while its verbalnominalization version

\section{Ruud's kicking the ball}

shows as a summary of event. Grammatically speaking, the two differ only in terms of their constructions, being clausal or phrasal. To decide whether a scene is to be construed as a sequence or summary, however, is not just a matter of selecting what type of 
construction is to employ. It requires complex cognitive processing such as conceiving and categorizing before an event or scene is linguistically manifested and represented.

\section{COMMUNICATIVE DYNAMISM}

1. An Overview of Communicative Dynamism

Communicative Dynamism (CD) is initiated and developed by noted figures of Prague School of linguistics, such as Mathesius and Firbas, based on Danes' model of three-level approach to syntax (Firbas, 2006: 225). In a nutshell, $C D$ is understood as

... quality, or aggregate of qualities, in a text which impels a reader through that text, and which 'pushes the communication forward'... [leading] the peaking of informativity towards the end of each gram-matical unit, whether clause or complex sentence... [giving] discourse a kind of forward momentum (Firbas, 1971: 136).

...an inherrent quality of communication and manifests itself in constant development towards the attainment of a communicative goal, in other words, towards the fulfilment of a communicative purpose. A linguistic element assumes some position in it and in accordance with this position displays a degree of communicative dynamism (Firbas, 2006:7).

While CG conceives grammatical constructions of various sorts as representations of cognitive processes, CD defines sentence and units of lower ranks such as clause, semi-clause, nominal phrase as

a distributional field of communicative dynamism in the act of communication, and their syntactic constituents (e.g. subject, predicative verb...) serve as communicative units. [A sentence is] a field of syntactic relations... a field within which the degrees of $C D$ are distributed, the distribution inducing the sentence to function in a particular perspective, i.e. perspectiving it towards the element carrying the highest degree of $C D$ (Firbas, 2006: 15-17).

\section{Perspective in Communicative Dynamism}

In $\mathrm{CD}$, perspective is to be understood with reference to the information structure or distributional field of communicative dynamism (Firbas, 2006: 5-6). It deals with which sentence segment or constituent is to bear the most communicative value within a construction. In line with this, other elements bearing less informational values are oriented toward the element bearing the most, viz. the sentence perspective. Name-wise, CDperspectiving is also called scaling of patterning of communication (GomezGonsales, 2001: 66-67). It is also concerned with the communicative purpose a sentence is meant to satisfy, namely, whether (a) to present one particular Phenomenon $(\mathrm{Ph})$, or (b) to ascribe a Quality $(Q)$ to the $P h$ priorly mentioned. In the former, it is called Presentative $(\mathrm{Pr})$ perspective. If this is 
the case, all other elements of a sentence are oriented toward the $S$ (ubject) acting as the $P h$ being presented. In the latter, the orientation is directed to other than the $S$, the other element bearing more informational value(s) than the $S$. As the $S$ no longer serves as the perspectived-element, its function in the informational structure recedes to that of B(earer of Quality). The perspective is, in turn, directed to the element that assigns quality to $B$. As such, it is called Q-perspective, being the $Q$ as the perspective. In short, $P h$ perspective is concerned with the dynamism of communication toward the $S$, while Q-perspective is the dynamism of communication away from it. CD-perspective is therefore concerned with which sentence segment constitutes the most dynamic element that completes the development of communication (Fribas, 2006: 5-6, 66).

Similar to CG-perspectiving, it is essentially the observer or speaker's (and in fact also the hearer/receptor's) autonomy to decide to which element the sentence is to be perspectived. Reciting the previous example

\section{The children ran around the house.}

the CD-perspective can be directed to The children, ran, or around the house (^-sign). What makes CG and CD differ significantly is the construct or rationale underlying the decision. While CG holds that the decision is reserved at the speaker's autonomy to determine importance and focus after cognitive processing takes place, CD posits that such a decision is essentially motivated by informative/communicative

valuation. The decision to which segment the perspective is directed is therefore a matter of assigning relative degree(s) of informational value in the realm of communication.

The next point to discuss is essentially practical and comparative: how does perspectiving in each of the two schools of thought work?

\section{CG-CD Perspectivising: A Comparative Account}

As noted above, CG posits that perspectiving is concerned with matters of viewpoint, importance, observer (speaker/writer), and focus (Saeed, 2003: 377). Meanwhile, CD holds that perspectiving is a matter of assigning relative degree(s) of informational value, namely whether the orientation is either toward the Subject (S-perspective, i.e. Presentative; the $S$ being the $P h$ presented) or away from the $S$ (Q(uality)-perspective) (Firbas, 2006: $6)$. The following table presents the underlying construct of $C G$ and $C D$ to deal with perspectiving.

Table 1 The underlying construct of CG and CD

\begin{tabular}{|l|l|l|}
\hline \multicolumn{1}{|c|}{ Construct } & \multicolumn{1}{c|}{ Cognitive Grammar } & Communicative Dynamism \\
\hline $\begin{array}{l}\text { Conception of } \\
\text { sentence }\end{array}$ & $\begin{array}{l}\text { As cognitive enterprise, } \\
\text { relation and interactions } \\
\text { among conceptual categories. } \\
\text { Sentence is reflection and } \\
\text { manifestation of cognitive } \\
\text { processes }\end{array}$ & $\begin{array}{l}\text { Sentence is manifestation of } \\
\text { how information or message } \\
\text { is structured and distributed } \\
\text { by relative degrees of } \\
\text { Communicative Dynamism. }\end{array}$ \\
\hline Categorization & Linguistic categories are & Multifunctional view: \\
\hline
\end{tabular}




\begin{tabular}{|c|c|c|}
\hline Construct & Cognitive Grammar & Communicative Dynamism \\
\hline & $\begin{array}{l}\text { basically cognitive and/or } \\
\text { conceptual models of reality }\end{array}$ & $\begin{array}{l}\text { syntactic, semantic, and } \\
\text { informational/ } \\
\text { communicative categories }\end{array}$ \\
\hline Perspectiving & $\begin{array}{l}\text { Cognitive mapping and } \\
\text { conceptualization of } \\
\text { importance and focus of } \\
\text { events, scenes }\end{array}$ & $\begin{array}{l}\text { Orientation and } \\
\text { informational valuation, } \\
\text { which element bears the } \\
\text { most informative; core }\end{array}$ \\
\hline $\begin{array}{l}\text { Key concepts in } \\
\text { perspectiving }\end{array}$ & $\begin{array}{l}\text { Spatial, motional, sequential, } \\
\text { summary, directionality, } \\
\text { locationality, importance, } \\
\text { focus, scenes, relations, } \\
\text { observer, participants forms } \\
\text { of interactions }\end{array}$ & $\begin{array}{l}\text { Informational value; relative } \\
\text { degree of informativeness; } \\
\text { bearer, setting, quality, } \\
\text { specification; foundation- } \\
\text { laying, core-consti-tuting, } \\
\text { rhematization }\end{array}$ \\
\hline $\begin{array}{l}\text { Nature of } \\
\text { relations }\end{array}$ & Conceptual, categorial & Functional, distributional \\
\hline
\end{tabular}

Since the decision to determine the perspective in a sentence is reserved at the hand of the speaker's autonomy, both CG and CD seem to agree that, as noted above, any of the three segments in The children ran around the house may become a potential perspective. The following scheme outlines their potentiality:

Table 2 The underlying construct of CG and CD

\begin{tabular}{|c|c|c|c|c|}
\hline & & & \\
\hline & & The children & ran & around the house \\
\hline \multicolumn{2}{|c|}{ Syntactic function } & Subject & Verb/Predicate & Adverb \\
\hline \multirow{2}{*}{\multicolumn{2}{|c|}{$\begin{array}{c}\text { Perspectiving in } \\
\text { Cognitive Grammar }\end{array}$}} & $\begin{array}{l}\text { Agent/ } \\
\text { doer }\end{array}$ & $\begin{array}{l}\text { Event/ } \\
\text { activity }\end{array}$ & $\begin{array}{l}\text { Scene: Locational- } \\
\text { Directional (SLD) }\end{array}$ \\
\hline & & $-/ \Lambda$ & $-/ \Lambda$ & $-/ \Lambda$ \\
\hline \multirow{3}{*}{$\begin{array}{c}\text { Perspectiving in } \\
\text { Communicative } \\
\text { Dynamism }\end{array}$} & (a) & $\begin{array}{c}\wedge \\
\text { Phenomenon } \\
\text { (R) }\end{array}$ & $\begin{array}{c}<<< \\
\text { Presentation }\end{array}$ & $\begin{array}{c}<<< \\
\text { Scene/Setting }\end{array}$ \\
\hline & (b) & $\begin{array}{l}\text { Bearer >>>> } \\
\text { (of Quality) }\end{array}$ & $\stackrel{\wedge}{\text { Quality (R) }}$ & $\begin{array}{c}<<< \\
\text { Setting }\end{array}$ \\
\hline & (c) & $\begin{array}{l}\text { Bearer >>>> } \\
\text { (of Quality) }\end{array}$ & $\begin{array}{c}>>> \\
\text { Quality }\end{array}$ & $\begin{array}{c}\wedge \\
\text { Specification (R) }\end{array}$ \\
\hline
\end{tabular}

Notes:

(1) $-/ \Lambda$; : alternative, potentially (or not potentially) perspectived element. In $\mathrm{CD}$, the segment being perspectived entails different naming for the other elements accordingly.

(2) Phenomenon, Quality, Bearer of Quality, Scene/Setting, and Specification are names of dynamic semantic functions (DSF). The DSF an element serves is determined relative to the other elements in the sentence concerned by virtue of four determining factors: context, semantics, linearity, and prosodics (Firbas, 2006: 10-11,115; Gomez-Gonzales, 2001: 66-68). The function an element serves is subject to change due to the factors mentioned above. 
(2) $>>>>$; $<<<<$ : nonperspectived segment(s) being oriented to the perspectived segment.

(3) (R): Rhematized, i.e. the peaking of information structure, the sentence segment or element being the most informative and dynamic.

In CG, regardless of which segment is perspectived $(\wedge)$, the conceptual categories and their interrelation is fixed and remains stable. Be it focused on The children, ran, or around the house, the role of each is reserved, respectively, as Agent/doer - Event/activity - Scene (Locational-Directional). In other words, the shift of perspectiving does not entail any change for the neighboring segment.

By contrast, the shift of perspectiving in $\mathrm{CD}$ bears significant difference, as shown in the three alternatives (a), (b), and (c). When it is perspectived toward the children, as in (a), the $S$ serves the dynamic function of $P h$ appearing on the scene of communication. In so doing, ran renders the function of presenting the $P h$ while around the house the Scene (or Setting). The children constitutes the perspective, viz. the most informative and dynamic element in the sentence concerned, to which all other segments are oriented. As such, the sentence demonstrates Presentation perspective.

Alternative (b) shows that the Verb/Predicate ran may become another alternative of perspectiving. If this happens, the segment the children is deemed less informative. It does not bear new information, hence no longer serves as the $\mathrm{Ph}$, but the $B o Q$ (Bearer of Quality). The verb ran qualifies the Subject, namely adding further information to it, and this very information of qualifying constitutes the perspective. The segment around the house serves as the Setting, and, compared to ran, is less informative/dynamic. In other words, both the children and around the house are oriented to ran being the perspective of the sentence.

Alternative (c) presents a potentially different perspective from (a) and (b). Here, both the children and ran do not constitute the perspective. Instead, they are oriented to around the house, being the most informative/dynamic segment in the sentence. As its function is to specify the children ran, it is called Specification (Sp). As the name suggests, the segment specifies the Quality ran, adding further information to it. When such a segment becomes the perspective, it renders the children $B o Q$ and ran $Q$. Being oriented to the Adverb, the sentence is perspectived toward the $S p$ of the Quality-perspective sentence. It is worth adding that not all adverbials are potentially perspectivable. Some may serve as Setting when they do not constitute the perspective in a sentence. To decide whether adverbials serve as Setting or Specification in a sentence goes beyond the scope of this article and is therefore intentionally excluded from the discussion.

As shown in the scheme above, CG-CD perspectiving may, of course, coincide on the same sentence segment. However, what is to bear in mind is that, while CG conceives the perspectived element as the one being important and focused, CD sees such a segment being the most dynamic and informative. Such a segment is called rhematized within a distributonal field of communicative dynamism. In this case, the CG's notion of important and focused on the one 
hand and CD's rhematization on the other seem to agree or coterminous.

However, as the theoretical constructs differ, it is reasonably common to observe that each of these two schools of thought demonstrates its peculiarity. While CG-perspectiving is essentially motivated by cognitive factors, CDperspectiving is driven by matters of relative informational value(s) or, better said, communicative considerations.

As observed in the scheme above, the shift of CG-perspectiving within a sentence does not bear different function(s) a sentence segment serves. This is presumably due to the cognitive categorial conceptions of the elements. In brief, CG tends to conceive relations among sentence elements in terms of relations among categories. By contrast, the shift of CDperspectiving from the $S$ to the $V / P r$ or to the $A d v$ does bear significant consequence in evaluating the informativeness/communicativenes $s$ of the each sentence segment. In other words, the dynamic semantic function a segment or element serves is subject to change due to the shift of perspective. Such a shift is decisive since perspectiving determines which sentence segment(s) constitutes the rheme or the most informative and dynamic element within the construction in the realm of communication (Firbas, 2006: 11). It seems reasonable to say that $C D$ tends to conceive relations among sentence elements in terms of relative functions rather than relations among categories.

As noted above, CG starts from the conceptual categories originating from cognitive processes. Interactions within a sentence are essentially interactions among conceptual categories, and such categories seem to be relatively stable within a construction. The role of context in conceiving relations and interactions seems to be independent from cognition. Meanwhile, what matters in CDperspectiving is the informational value assigned to a segment relative to the verbal-situational context (Firbas, 2006: 21-40). Relations among sentence elements are in nature functional rather than categorial, and being so, subject to change whenever it is deemed necessary.

Recalling the definition of communicative dynamism, the three alternatives (a), (b), and (c) also display the notion of aggregate of qualities. Be it the $S, V / P r$, or $A d v$, CD-perspectiving instigates the other sentence segments or elements to 'adjust' and 'act' accordingly, semantically and dynamically. Once the perspectived element is established, the others are oriented to such element bearing the 'aggregate of qualities', to be the most dynamic one in a distributional field of communicative dynamism.

\section{E. Conclusion}

Perspectiving in $\mathrm{CG}$ is essentially cognitively-driven and resides in the observer/ speaker's autonomy to select the viewpoint of determining importance and focus, all relying on the relations among conceptual categories such as space, motion, and position. Perspectiving is therefore a matter of cognitive enterprise and to a great extent reserves the dictionary definition and any of the four ways Cruse outlines of seeing things or objects in ordinary life.

Meanwhile, the notion of CDperspectiving seems to share only two of the four ways Cruse outlines, namely (b) as a kind, in contrast 
with other kinds; and (c) as having a certain function. With respect to (b), CD-perspectiving shows how a particular sentence segment is perspectived relative to other segments. This implies that there are relative degrees of informational value, and the notion of degrees assumes some sort of contrasting one to another. In line with Cruse's point (c), CD-perspectiving does demonstrate the idea of function, as shown in the different naming of dynamic semantic function(s) a segment serves. The perspectived sentence segment being the orientation for the other segments within the construction thus serves the function of holding the 'aggregate of qualities'.

In terms of speaker's autonomy for perspectiving, CG and $C D$ share the same view. In $C D$, however, perspectiving is essentially a matter of informational structuring and of determining to which sentence segment orientation is directed. At this juncture, it is similar to the CG concept of importance and focus, of informational valuating leading to the peaking of informativeness named rhematization in CD. Relations among sentence elements are basically functional-informational. CD-perspectiving is not primarily concerned with the sense of space and motion as CG-perspectiving is. Rather, it is understood in the judgmental sense, namely, of weighting relative informational value of sentence segments in the distributional field of communicative dynamism.

\section{REFERENCES}

Cruse, A. (2000). Meaning in Language: An Introduction to Semantics and Pragmatics.
Oxford: Oxford University Press.

de Beaugrande, R A and Dressler, W U. (1990). Introduction to Text Linguistics. London: Longman.

Firbas, J. (1971). On the Concept of Communicative Dynamism in the Theory of Functional Sentence Perspective dlm. Universitas Brunensis, Studia Minora A.19.

Firbas, J. (2006). Functional sentence perspective in written and spoken communication. Cambridge: Cambridge University Press.

Gomez-G, Maria A. (2001). The Theme-Topic Interface: Evidence from English. Amsterdam: John Benjamins.

Kemmer, S. About Cognitive Linguistics: Historical Background. available in http://www.cogling.org/rese arch.shtml; downloaded Sept. 24, 2008.

Langacker, R W. (1987). Foundations of Cognitive Grammar, vol. 1. Stanford, CA: Stanford University Press.

Langacker, R W. (1991). Foundations of Cognitive Grammar, vol. 2: Descriptive Applications. Stanford, CA: Stanford University Press.

Procter, P (ed. in chief). (1981). LDOCE: Longman Dictionary of Contemporary English London: Longman. 
Saeed, J I. (2003). Semantics. Oxford: Blackwell Publishing.

Trask, R.L. (1993). A Dictionary of Grammatical Terms in Linguistics. London: Routledge.

van Valin, Robert D., and Lapolla, R J. (1999). Syntax: Structure,
Meaning, and Function. Cambridge: Cambridge University Press.

Victoria N and David B. G (eds. in chief). (1996). Webster's New World College Dictionary. New York: Simon \& Schuster.

Wikipedia Encyclopedia Online 